\title{
Clinical utility of low-density lipoprotein particle measurement in management of cardiovascular disease: a case report
}

This article was published in the following Dove Press journal:

Research Reports in Clinical Cardiology

26 April 201 I

Number of times this article has been viewed

\author{
Tara L Dall' \\ Ray Pourfarzib² \\ 'Advanced Lipidology, Delafield,WI, \\ USA; ${ }^{2}$ LipoScience Inc, Raleigh, \\ NC, USA
}

Correspondence: Tara Dall

Advanced Lipidology, 524 Milwaukee Street \#I80, Delafield,WI 53018, USA

Tel + I 2626463223

Fax +I 2626463443

Email taradall@advlip.com

\begin{abstract}
Despite adequate screening and low-density lipoprotein cholesterol (LDL-C)-lowering therapy, it has been recognized that many patients with low or moderate LDL-C levels experience cardiovascular events. Furthermore, many patients with cardiovascular disease and relatively normal levels of LDL-C have increased levels of low-density lipoprotein particles (LDL-P). The purpose of this case report is to illustrate the importance of LDL-P in the surprising presentation of vascular disease in a woman who had a high concentration of high-density lipoprotein cholesterol (HDL-C). By utilizing lipoprotein information, patients can be appropriately selected to receive suitable medication, leading to better health outcomes.
\end{abstract}

Keywords: lipoprotein particle concentration, premature coronary artery disease, lipid profile, combination therapy, vitamin D deficiency

\section{Introduction}

Does a traditional cholesterol test give reliable information to the health care provider in managing cardiovascular disease in their patients? Low-density lipoprotein cholesterol (LDL-C) has long been the basis for measuring coronary heart disease risk because its measurement is relatively easy. Despite adequate screening and LDL-lowering therapy, it has been recognized that many patients with low or moderate LDL-C levels experience coronary heart disease events. ${ }^{1}$ In 2007, a seven-member panel of experts developed a consensus statement that was endorsed by America Diabetes Association and the American College of Cardiology, which concluded that lipoprotein abnormalities are common findings in patients with cardiometabolic risk. ${ }^{2}$ Moreover, many patients with cardiometabolic risk have relatively normal levels of LDL-C, yet have increased levels of low-density lipoprotein particles (LDL-P).

Furthermore, clinical trials that have compared the clinical outcomes in incident cardiovascular events between LDL-C versus LDL-P concentration, consistently demonstrate that LDL-P concentration, or its surrogate measure, apolipoprotein B (Apo B), are more predictive of cardiovascular events than LDL-C. ${ }^{3}$ Moreover, therapies that lower lipids may have varying effects on LDL-C versus LDL-P. For instance, statins, estrogen replacement therapy, and a low-fat, high-carbohydrate diet tends to lower cholesterol content in the LDL particles more than they lower LDL-P concentration. Conversely, fibrates, nicotinic acid, some thiazolidinediones (pioglitazone), exercise, and a low carbohydrate diet tend to lower LDL-P concentration more than they lower LDL-C content in LDL particles (Table 1). ${ }^{3}$ Therefore, reliance on LDL-C as a biomarker may not fully appreciate the benefit of these therapies. Hence, recent consensus papers from the American Association for Clinical Chemistry have focused 
Table I Interventions that changes LDL composition (size or cholesterol content) will differentially affect LDL-C and LDL-P concentrations

\begin{tabular}{ll}
\hline $\begin{array}{l}\text { Interventions that increases } \\
\text { cholesterol per particle } \\
\text { (LDL-P concentration }\end{array}$ & $\begin{array}{l}\text { Interventions that decreases } \\
\text { cholesterol per particle } \\
\text { (LDL-C concentration } \\
\text { decreases more) }\end{array}$ \\
\hline Fibrates & Statins \\
Niacin & Statins + ezetimibe \\
Glitazones (some) & Estrogen replacement therapy \\
Omega 3 fatty acids & Antiretrovirals (some) \\
Exercise & High carbohydrate diet \\
Low carbohydrate diet &
\end{tabular}

Notes: Reprinted from Rosenson R, Davidson M, Pourfarzib R. Underappreciated opportunities for low-density lipoprotein management in patients with cardiometabolic residual risk. Atherosclerosis. 2010;213:1-7, with permission from Elsevier. ${ }^{3}$

Abbreviations: LDL, low-density lipoprotein; LDL-C, low-density lipoprotein cholesterol; LDL-P, low-density lipoprotein particles.

on measurement of LDL-P and Apo B rather than LDL-C for both risk assessment and therapeutic effectiveness. ${ }^{4}$

The purpose of this case report is to illustrate the importance of LDL-P in the surprising presentation of vascular disease in a woman with a high concentration of high-density lipoprotein cholesterol (HDL-C). We will also discuss the discordance between LDL-P and LDL-C concentrations and the benefit of knowing the concentrations of various lipoproteins in coronary heart disease patients. We will discuss evidence supporting the treatment strategies and end with clinical recommendations.

\section{Case report}

A healthy 57-year-old Caucasian woman with a family history of premature coronary artery disease presented to her primary care physician for preventive screening. She reported eating a healthy diet, exercising regularly, and consuming minimal alcoholic beverages. Her mother and sister had coronary artery disease and had had coronary bypass surgery at the ages of 52 years and 53 years, respectively.

The patient's lipid panel revealed total cholesterol 250 mg/dL, LDL-C 110 mg/dL, HDL-C 116 mg/dL, triglycerides $29 \mathrm{mg} / \mathrm{dL}$, and non-HDL-C $134 \mathrm{mg} / \mathrm{dL}$ (Table 2). HDL-C values had been elevated $>100 \mathrm{mg} / \mathrm{dL}$ for several years. It is possible that these values may have been due to laboratory artifact. If the laboratory uses phosphotungstic acid for precipitation of the B-containing lipoproteins, the lipoprotein(a) may remain in the supernatant and be measured as HDL-C. In this patient's case, she had had elevated HDL-C measured in more than one laboratory over the course of several years and it was consistently greater than $100 \mathrm{mg} / \mathrm{dL}$.

Based on the patient's risk factors of age and family history, a Framingham risk score was performed, and a $3 \%$ risk for heart attack or stroke in the next 10 years was calculated. She was given advice to continue a hearthealthy diet and regular exercise, with no recommendation for medical therapy other than aspirin $81 \mathrm{mg} /$ day. She was also told she had cardiovascular protection based on her high HDL-C.

Two months after this screening test, the patient experienced an episode of atypical chest pain. She was evaluated in the emergency room. No cardiac work-up was performed because she responded to treatment with antacids and proton pump inhibitor therapy. Two weeks later she again began to experience nonexertional, atypical chest pain. She was again evaluated in the emergency room and at this time had an abnormal electrocardiogram, and subsequent heart catheterization showed coronary disease with $70 \%$ blockage in the left anterior descending artery and diffuse disease in multiple vessels. She underwent triple vessel coronary artery bypass surgery. Upon discharge, her cardiologist placed her on atorvastatin $40 \mathrm{mg}$, omega 3 fatty acids $1 \mathrm{~g}$, aspirin $81 \mathrm{mg}$, and clopidogrel $75 \mathrm{mg}$ per day.

One month later she was evaluated in the author's lipid clinic. Her lipid panel on atorvastatin $40 \mathrm{mg}$ revealed total cholesterol $203 \mathrm{mg} / \mathrm{dL}$, LDL-C $141 \mathrm{mg} / \mathrm{dL}$, HDL-C $44 \mathrm{mg} / \mathrm{dL}$, triglycerides $89 \mathrm{mg} / \mathrm{dL}$, and non-HDL-C $159 \mathrm{mg} / \mathrm{dL}$. Her nuclear magnetic resonance lipoprotein test results on atorvastatin $40 \mathrm{mg}$ revealed a total LDL-P of $3002 \mathrm{nmol} / \mathrm{L}$, all of which were small LDL-P. Other laboratory tests performed are listed in Table 2. Of note, she had elevated high-sensitivity C-reactive protein, elevated lipoprotein(a) and severe vitamin D deficiency. Based on the American Diabetes Association/American College of Cardiology and American Association for Clinical Chemistry consensus treatment goals of Apo B $<80 \mathrm{mg} / \mathrm{dL}$, non-HDL-C $<100 \mathrm{mg} / \mathrm{dL}$, and LDL-P $<1100 \mathrm{nmol} / \mathrm{L}$, the patient's residual risk was more aggressively managed. ${ }^{2,4}$

\section{Evaluation and management}

The patient was a woman with known coronary artery disease and a strong family history of coronary disease. She was not treated initially, based on a traditional lipid panel showing high HDL-C and presumed protection. Although in general, high levels of HDL-C are associated with reduction for coronary artery disease, some individuals may have dysfunctional HDL-C that is not protective. Her LDL-C value of $110 \mathrm{mg} / \mathrm{dL}$ was not treated based on current National Cholesterol Education Panel guidelines. After subsequent analysis on atorvastatin $40 \mathrm{mg}$, nuclear magnetic resonance lipoprotein test results revealed a significantly elevated risk based on an LDL-P of $3002 \mathrm{nmol} / \mathrm{L}$ (Table 2). 


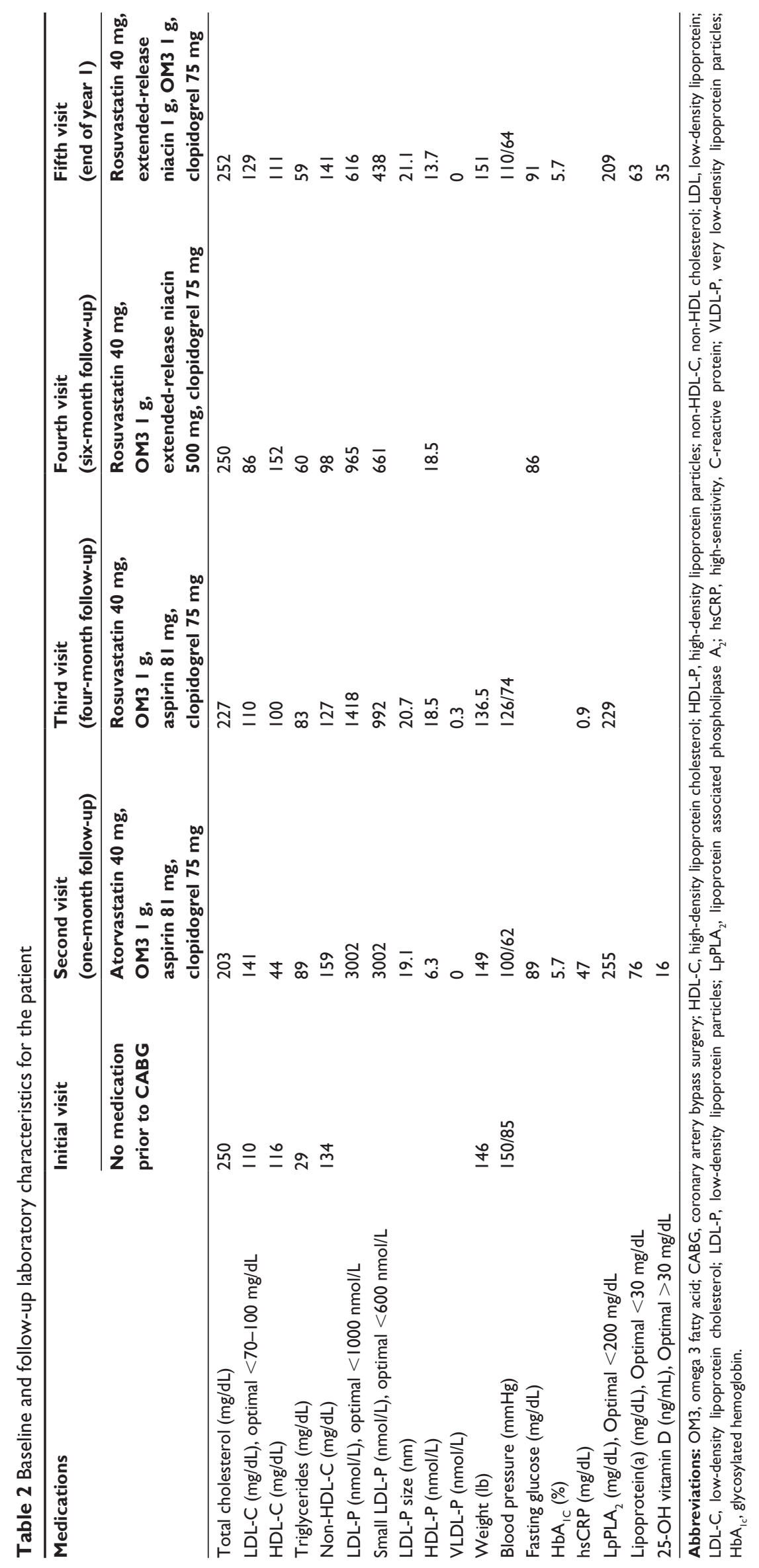


In her case, LDL-P was dramatically elevated, despite being on atorvastatin $40 \mathrm{mg}$, so we elected to switch her to rosuvastatin $40 \mathrm{mg}$. A recently published, randomized, double-blind, controlled study demonstrated greater LDL-P reduction with rosuvastatin versus atorvastatin. ${ }^{5}$ Four months later, after a weight loss of $9 \mathrm{lb}$ and switching to rosuvastatin, her LDL-P dropped to $1418 \mathrm{nmol} / \mathrm{L}$, small LDL-P dropped to $992 \mathrm{nmol} / \mathrm{L}$, and HDL-C increased back to $100 \mathrm{mg} / \mathrm{dL}$. LDL-C was now $110 \mathrm{mg} / \mathrm{dL}$, triglycerides $83 \mathrm{mg} / \mathrm{dL}$, and total cholesterol $227 \mathrm{mg} / \mathrm{dL}$. Her high sensitivity C-reactive protein normalized to $0.9 \mathrm{mg} / \mathrm{dL}$. Due to vitamin D deficiency, she was also initiated on treatment with over-the-counter vitamin D3 5000 IU/day.

With known coronary disease, elevated lipoprotein(a), and LDL-P still not to target, we added extended-release niacin $500 \mathrm{mg}$. Extended-release niacin and estrogen are two of the few agents known to lower lipoprotein(a), although there are no prospective data to suggest lowering lipoprotein(a) has any impact on cardiovascular disease event reduction. Extended-release niacin has also been shown to lower LDL particle concentration. ${ }^{6}$

On rosuvastatin $40 \mathrm{mg}$ and extended-release niacin $500 \mathrm{mg}$, nuclear magnetic resonance revealed LDL-P 965 nmol/L, small LDL-P $661 \mathrm{nmol} / \mathrm{L}$, Apo B 72 mg/dL, LDL-C $86 \mathrm{mg} / \mathrm{dL}$, triglycerides $60 \mathrm{mg} / \mathrm{dL}$, total cholesterol $250 \mathrm{mg} / \mathrm{dL}$, HDL-C $152 \mathrm{mg} / \mathrm{dL}$, and non-HDL-C $98 \mathrm{mg} / \mathrm{dL}$. She had now met goals based on an America Diabetes Association and the American College of Cardiology consensus statement of Apo B $<80 \mathrm{mg} / \mathrm{dL}$ and nonHDL-C $<100 \mathrm{mg} / \mathrm{dL}^{2}{ }^{2}$ She still had elevated LDL-P of $965 \mathrm{nmol} / \mathrm{L}$ (20th percentile of Framingham population), elevated LDL-C $86 \mathrm{mg} / \mathrm{dL}$, and elevated lipoprotein(a), so titration to extended-release niacin $1 \mathrm{~g}$ was done. Exactly one year after her coronary artery bypass surgery, she had a traditional lipid panel of total cholesterol $252 \mathrm{mg} / \mathrm{dL}$, LDL-C $129 \mathrm{mg} / \mathrm{dL}$, HDL-C $111 \mathrm{mg} / \mathrm{dL}$, and triglycerides $59 \mathrm{mg} / \mathrm{dL}$. As illustrated in Table 2, her traditional lipid panel was no different on rosuvastatin $40 \mathrm{mg}$ and extended-release niacin $1 \mathrm{~g}$, a potent combination drug therapy, than when she was on no therapy prior to her bypass surgery. However, her LDL-P levels declined from $3002 \mathrm{nmol} / \mathrm{L}$ to $616 \mathrm{nmol} / \mathrm{L}$ at the end of one year of treatment.

\section{Recommendations}

It is well documented that the cholesterol and triglyceride content of LDL particles varies from person to person because of differences in particle size and lipid composition. ${ }^{7-9}$ Hence, two patients who have the same measured LDL-C concentrations can have significantly different numbers of LDL particles and therefore a different risk for coronary heart disease. ${ }^{10,11}$ Strong evidence now exists for the superiority of lipoprotein measurements versus lipid concentrations in the management of coronary heart disease (Table 3). 3,7,9 For example, in the Framingham Offspring Study, the 15-year risk of cardiovascular disease events among 3066 middle-aged men and women was related to LDL-P, and not LDL-C, in individuals with discordant values for these two measures of LDL. The data indicate that LDL-C performs well as a surrogate for LDL-related cardiovascular disease risk when values are in agreement (ie, concordant) with LDL-P, but less well when they are discordant. ${ }^{7}$ Furthermore, recently published data from the Multi-Ethnic Study of Atherosclerosis showed that in individuals with discordant LDL-C and LDL-P levels, the LDL-attributable atherosclerotic risk was better indicated by LDL-P. For the discordant levels of LDL-P and LDL-C, only LDL-P was associated with incident cardiovascular disease.

In our lipid clinic, we use nuclear magnetic resonance as a useful tool to distinguish between patients warranting an aggressive treatment approach and those warranting a less aggressive treatment approach. What we have found in our adult population is that in patients with high risk, ie, known cardiovascular disease or diabetes, combination drug therapy decreases lipoprotein levels effectively (combination of statins with extended release-niacin, fibrates, thiazolidinediones, and omega-3 fatty acids). ${ }^{3,11}$ In patients with insulin resistance as the core etiology of dyslipidemia, weight loss, increased exercise, and lower carbohydrate diets will also favorably decrease LDL-P. ${ }^{3,11}$

\section{Conclusion}

In a patient with a strong family history for coronary heart disease, even in the presence of a high HDL-C, a more extensive evaluation may identify nontraditional risk factors, such as elevated LDL-P, thus placing individuals at increased risk for coronary heart disease. Furthermore, many high-risk patients who achieve LDL-C and non-HDL-C target levels will not have achieved low population-equivalent LDL-P targets. By utilizing lipoprotein information, appropriate patient selection will identify those who should receive suitable medication, leading to better health outcomes. 


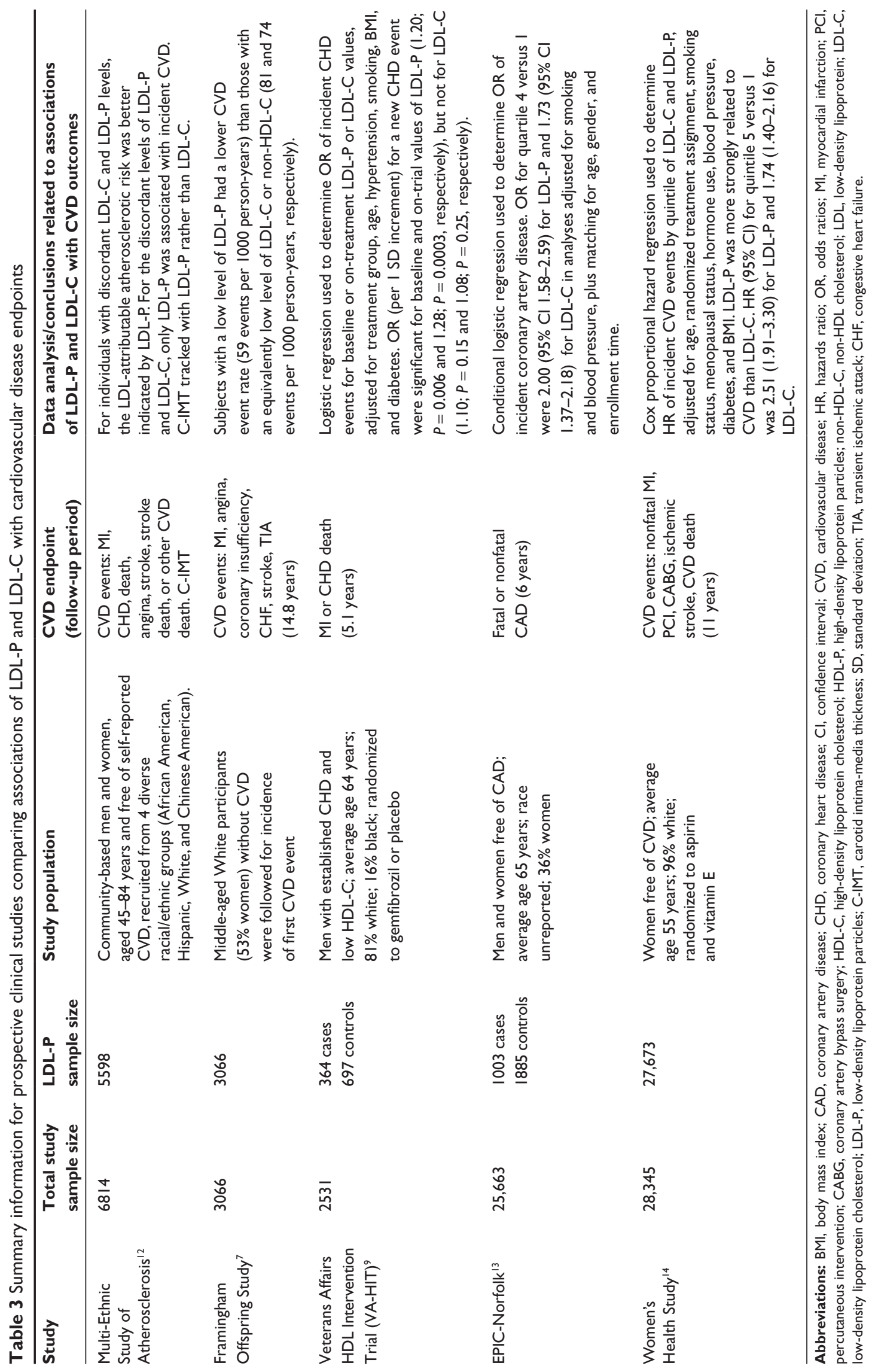




\section{List of abbreviations}

AACC, American Association for Clinical Chemistry; ACC, American College of Cardiology; ADA, American Diabetes Association; Apo B, Apolipoprotein B; CMR, Cardiometabolic risk; C-IMT, Carotid intima-media thickness; CABG, Coronary bypass surgery; ER, Emergency room; HDL-C, High-density lipoprotein cholesterol; HDL-P, High-density lipoprotein particles; Non-HDL-C, Non HDL Cholesterol; LDL-C, Low-density lipoprotein cholesterol; LDL-P LDL, particle concentration; LpPLA, Lipoprotein associated phospholipase $\mathrm{A}_{2}$; MESA, Multi-Ethnic Study of Atherosclerosis; MI, Myocardial infarction; OM3, Omega 3 fatty acid; VLDL-P, Very low-density lipoprotein particle.

\section{Disclosure}

TD serves on the speaker bureaus for Abbott, GlaxoSmithKline, LipoScience, Merck Schering Plough, Takeda, and Santarus. RP serves as Vice President of Medical Affairs at LipoScience.

\section{References}

1. Hsia J, Otvos JD, Rossouw JE, et al. Lipoprotein particle concentrations may explain the absence of coronary protection in the Women's Health Initiative hormone trials. Arterioscler Thromb Vasc Biol. 2008;28: 1666-1671.

2. Brunzell JD, Davidson M, Furberg CD, et al. Lipoprotein management in patients with cardiometabolic risk: Consensus statement from the American Diabetes Association and the American College of Cardiology foundation. Diabetes Care. 2008;31:811-822.

3. Rosenson R, Davidson M, Pourfarzib R. Underappreciated opportunities for low-density lipoprotein management in patients with cardiometabolic residual risk. Atherosclerosis. 2010;213:1-7.
4. Contois JH, McConnell JP, Sethi AA, et al. Apolipoprotein B and Cardiovascular Disease Risk: Position Statement from the American Association for Clinical Chemistry Lipoproteins and Vascular Diseases Division Working Group on Best Practices. Clin Chem. 2009;55:407-419.

5. Rosenson RS, Otvos JD, Hsia J. Effects of rosuvastatin and atorvastatin on low-density and high-density lipoprotein particle concentrations in patients with the metabolic syndrome: A randomized, double-blind, controlled study. Diabetes Care. 2009;32:1087-1091.

6. Jafri H, Alsheikh-Ali AA, Mooney P, Kimmelstiel CD, Karas RH, Kuvin JT. Extended-release niacin reduces LDL particle number without changing total LDL cholesterol in patients with stable CAD. J Clin Lipidol. 2009;3:45-50.

7. Cromwell WC, Otvos JD, Keyes M, et al. LDL Particle number and risk of future cardiovascular disease in the Framingham Offspring Study implications for LDL management. J Clin Lipidol. 2007;1:583-592.

8. Cromwell WC, Otvos JD. LDL particle number is highly heterogeneous among patients with type 2 diabetes at an LDL cholesterol target goal $<100$ mg/dL. Am J Cardiol. 2006;98:1599-1602.

9. Otvos J, Collins D, Freedman D, et al. VA-HIT: Low density lipoprotein and high density lipoprotein particle subclasses predict coronary events. Circulation. 2006;113:1556-1563.

10. Jeyarajah E, Cromwell W, Otvos J. Lipoprotein particle analysis by nuclear magnetic resonance spectroscopy. Clin Lab Med. 2006;26: 847-870.

11. Cromwell WC, Bays HE, Toth PP. Lipoprotein subfraction analysis using nuclear magnetic resonance spectroscopy. In: Adams J, Apple F, Jaffe A, editors. Clinical Applications of Markers in Cardiology: A Case-Oriented Approach. London, UK: Blackstone; 2007.

12. Otvos JD, Mora S, Shalaurova I, Greenland P, Mackey RH, Goff DC. Clinical implications of discordance between low-density lipoprotein cholesterol and particle number. J Clin Lipidol. 2011;5:105-113.

13. El Harchaoui K, van der Steeg WA, Stroes ES, et al. Value of low-density lipoprotein particle number and size as predictors of coronary artery disease in apparently healthy men and women: The EPIC-Norfolk Prospective Population Study. J Am Coll Cardiol. 2007;49:547-553.

14. Mora S, Otvos JD, Rifai N, Rosenson RS, Buring JE, Ridker PM. Lipoprotein particle profiles by nuclear magnetic resonance compared with standard lipids and apolipoproteins in predicting incident cardiovascular disease in women. Circulation. 2009;119:931-939.

\section{Publish your work in this journal}

Research Reports in Clinical Cardiology is an international, peerreviewed, open access journal publishing original research, reports, editorials, reviews and commentaries on all areas of cardiology in the clinic and laboratory. The manuscript management system is completely online and includes a very quick and fair peer-review system.

\section{Dovepress}

Visit http://www.dovepress.com/testimonials.php to read real quotes from published authors. 